\title{
Is Retinal Assessment still Useful for Cardiovascular Risk Stratification in the Modern Era?
}

\author{
Ryo Kawasaki 1, 2, 3, 4 \\ ${ }^{1}$ Artificial Intelligence Center for Medical Research and Application, Osaka University Hospital, Osaka, Japan \\ ${ }^{2}$ Department of vision informatics, Osaka University Graduate School of Medicine, Osaka, Japan \\ ${ }^{3}$ Department of Public Health, Fukushima Medical University Graduate School of Medicine, Fukushima, Japan \\ ${ }^{4}$ Department of Clinical Research, Southern University of Denmark, Odense, Denmark
}

\section{See article vol. 29: 000-000}

In the paper published by Matsuoka et al. ${ }^{1)}$, the authors examined whether retinal assessment provided in certain health checkups in Japan (namely, "TokuteiKenko-Shinsa") can provide cardiovascular disease (CVD) risk stratification along with the 2017 American College of Cardiology/American Heart Association Blood Pressure guidelines. They observed higher CVD risks in persons with retinal arteriolosclerotic signs compared with those without. One of the major findings was related to myocardial infarction. Persons with stage 1 hypertension with retinal arteriolosclerotic signs of Keith-WagenerBarker (KWB) grade 1 or more were at a significantly higher risk of myocardial infarction compared with those who have normal blood pressure (adjusted hazard ratio [HR]: $1.86 ; 95 \%$ confidence interval [CI]: 1.17-2.95), whereas persons with stage 1 hypertension without retinal arteriolosclerotic signs were not significantly associated with a higher risk after adjusting for age, sex, obesity, high waist circumference, diabetes mellitus, dyslipidemia, and cigarette smoking (HR: 1.17; 95\% CI: 0.93-1.47).

Matsuoka et al. ${ }^{1)}$ have demonstrated that even in modern Japan, retinal assessment can contribute to the risk stratification of CVD. The clinical interpretation of this finding is straightforward. Persons with mild hypertension of stage 1 with retinal arteriosclerosis are already at a higher risk of myocardial infarction compared with those without retinal signs.

Since Keith, Wegener, and Barker reported that retinal vascular arteriolosclerotic signs in persons with hypertension can clearly stratify the risk of mortality in $1939^{2)}$, retinal assessment has been used to monitor vascular health in vivo in persons with hypertension. However, given the improved management and prevention of hypertension, severe hypertensive organ damage has become rare, and there is a criticism that retinal assessment is not useful in the clinical management of hypertension ${ }^{3)}$. Nevertheless, there have been studies to reevaluate the role of retinal assessment in CVD risk stratification in persons with hypertension in the last few decades ${ }^{4)}$, which have suggested that retinal assessment with quantitative retinal vessel caliber measurements can provide information independent of hypertension or blood pressure. A previous study has also suggested that retinal arteriolar narrowing can precede the incidence of hypertension ${ }^{5)}$.

I believe that the study by Matsuoka et al. highlighted two important aspects of retinal assessment in the context of stratifying CVD risks in Japan today. First, it suggests that retinal assessment is still useful in this modern era for patients with a milder stage of hypertension and milder signs of KWB grade 1 or more. Second, retinal assessment in certain health checkups in Japan can contribute to detailed CVD risk stratification. It is important to discuss whether it is worth continuing retinal assessment in screening programs. In reality, retinal assessments in the health checkups in Japan are not provided universally; only selected screening centers or clinics provide an optional examination, e.g., only $17.6 \%$ individuals in the National Health Insurance underwent a retinal assessment in $2018^{\circ}$. If we leave this suboptimal situation as it is, we should reconsider whether retinal assessments should be continued in health checkups. In contrast, there is an emerging concept of revamping retinal assessments with deeplearning models without extracting specific signs ${ }^{7}$, which may lead to a completely new era of health

Address for correspondence: Ryo Kawasaki, Artificial Intelligence Center for Medical Research and Application, Osaka University Hospital, Osaka, Japan E-mail: ryo.kawasaki@ophthal.med.osaka-u.ac.jp

Received: December 24, $2021 \quad$ Accepted for publication: January 17, 2022

Copyright@2022 Japan Atherosclerosis Society

This article is distributed under the terms of the latest version of CC BY-NC-SA defined by the Creative Commons Attribution License. 
checkups. The usefulness of retinal assessment for cardiovascular risk stratification is an exciting area for further research.

\section{COI}

Ryo Kawasaki has received research funding from Senju and an endowed-department professorship from Topcon not related to this editorial.

\section{References}

1) Matsuoka S, Kaneko H, Kamon T, Suzuki Y, Yano Y, Okada A, Itoh H, Morita K, Fukui A, Fujiu K, Michihata N, Jo T, Takeda N, Morita H, Nakamura S, Yokoo T, Nishiyama A, Node K, Yasunaga H, Komuro I. Incorporation of Retinal Arteriolosclerosis into Risk Stratification of Blood Pressure Category According to the 2017 ACC/AHA Blood Pressure Guideline. J atheroscler Thromb, 2021; in press. doi: https: //doi.org/10.5551/ jat.63262

2) Keith NM, Wagener HP, Barker NW. Some different types of essential hypertension: their course and prognosis.
Am J Med Sci, 1939; 197: 332-343

3) van den Born BJ, Hulsman CA, Hoekstra JB, Schlingemann RO, van Montfrans GA. Value of routine funduscopy in patients with hypertension: systematic review. BMJ, 2005; 331: 73

4) Wong TY, Mitchell P. Hypertensive retinopathy. N Engl J Med, 2004; 351: 2310-2317

5) Ding J, Wai KL, McGeechan K, Ikram MK, Kawasaki R, Xie J, Klein R, Klein BB, Cotch MF, Wang JJ, Mitchell P, Shaw JE, Takamasa K, Sharrett AR, Wong TY; Meta-Eye Study Group. Retinal vascular caliber and the development of hypertension: a meta-analysis of individual participant data. J Hypertens, 2014; 32: $207-$ 215

6) Yokoyama T, Hiratsuka Y, Yamada M. Trend in the retinal assessment in the specific health check-ups. 2018 Health Labour Sciences Research Grant report. (https: //mhlwgrants.niph.go.jp/system/files/report_pdf/201909026Abuntan4.pdf)

7) Poplin R, Varadarajan AV, Blumer K, Liu Y, McConnell MV, Corrado GS, Peng L, Webster DR. Prediction of cardiovascular risk factors from retinal fundus photographs via deep learning. Nat Biomed Eng, 2018; 2: 158-164 